\title{
Psychomotor Development of Children from an lodine-Deficient Region
}

\author{
Maria José Costeira, MD, PhD, Pedro Oliveira, PhD, Nadine Correia Santos, PhD, Susana Ares, MD, PhD, \\ Belen Saenz-Rico, PhD, Gabriella Morreale de Escobar, PhD, and Joana Almeida Palha, PhD
}

\begin{abstract}
Objectives To assess the psychomotor development of the progeny of women from a moderately iodinedeficient area for whom thyroid function during pregnancy was measured.

Study design The development of 86 children was assessed by the Bayley Scale of Infant Development at 12, 18, and 24 months.

Results Maternal serum free thyroxine $\left(\mathrm{FT}_{4}\right)$ levels in the first trimester of pregnancy were the major determinant of psychomotor development at 18 and 24 months. Children born from mothers with $\mathrm{FT}_{4}$ levels $<25$ th percentile $(<10$ $\mathrm{pg} / \mathrm{mL}$ ) had an OR of 2.1 for mild-to-severe delay. Furthermore, alterations in behavior were already observed at 12 months and were related to subsequent changes in development. Neonatal thyroid status did not influence development.
\end{abstract}

Conclusions This study highlights the need to implement active measures of iodine supplementation periconceptionally and during pregnancy and lactation because the negative effects on development and behavior might be prevented through preemptive action. (J Pediatr 2011; $\mathbf{\square} \mathbf{\square}-\mathbf{\square})$.

dequate amounts of thyroid hormones are critical for nervous system function throughout life, but particularly during development. Thyroid hormones regulate cerebral cytoarchitecture, neuronal growth, and synaptogenesis, and their receptors are widely distributed in the central nervous system. ${ }^{1-5}$ The fetus relies on the mother for the supply of thyroid hormones because its thyroid only secretes significant amounts of thyroxine $\left(\mathrm{T}_{4}\right)$ after midgestation. Accordingly, maternal hypothyroxinemia, regardless of the cause, leads to decreased availability of $\mathrm{T}_{4}$ for the fetal brain and has been described to impair neuropsychological development in the progeny. ${ }^{6}$

Iodine is required for thyroid hormone synthesis, and an adequate iodine intake is necessary for thyroid hormone homeostasis. The World Health Organization states that iodine deficiency (ID), the major cause of maternal hypothyroxinemia (regardless of whether the mother has normal thyroid function), is the greatest contributing factor, after starvation, to mental retardation in children. The most serious consequence of ID is neurologic cretinism in areas of severe deficiency (urinary iodine [UI] excretion $<25 \mu \mathrm{g} / \mathrm{L}$ ), but, of note, children's development is still affected in areas of mild to moderate deficiency (UI excretion 25 to $100 \mu \mathrm{g} / \mathrm{L})^{7}$

Normal infant development is a global process by which the child acquires complex skills and knowledge. Development is a continuous, dynamic, and irreversible progression that encompasses three main development domains: cognitive, motor, and psychosocial. Satisfactory cognitive and motor development requires a well-formed and normally functioning nervous system, as well as an environment that provides adequate nutrition, opportunities to learn and practice, challenges and rewards. ${ }^{8}$ Furthermore, it is recognized that, altogether, genetics, in utero environment, and individual intrinsic postnatal factors cannot be dissociated from the child's immediate (family) and broader social (community, political, and social structure) environment, and that the impact of this interaction has repercussions throughout life. ${ }^{9,10}$

Maternal hypothyroidism ${ }^{11,12}$ and hypothyroxinemia ${ }^{12-16}$ are related to adverse psychomotor development. Hypothyroxinemia is also linked to attention deficit, hyperactivity disorders ${ }^{17}$ and autism, influencing mood and behavior. ${ }^{18}$ More specifically, studies from ID areas show a correlation between maternal serum $\mathrm{T}_{4}$ levels and subsequent motor and cognitive function in children ${ }^{19}$ and between mothers with hypothyroxinemia and impaired intellectual and motor function of progeny. ${ }^{20}$

\begin{tabular}{|ll|}
\hline $\mathrm{FT}_{3}$ & Free triiodothyronine \\
$\mathrm{FT}_{4}$ & Free thyroxine \\
$\mathrm{ID}$ & lodine deficiency \\
$\mathrm{MDI}$ & Mental Development Index \\
$\mathrm{PDI}$ & Psychomotor Development Index \\
$\mathrm{T}_{4}$ & Thyroxine \\
$\mathrm{TT}_{3}$ & Total triiodothyronine \\
$\mathrm{TT}_{4}$ & Total thyroxine \\
$\mathrm{TSH}$ & Thyroid stimulating hormone \\
$\mathrm{UI}$ & Urinary iodine \\
\hline
\end{tabular}

From the Life and Health Sciences Research Institute, School of Health Sciences (M.C., N.S. J.P.), Department of Production \& Systems Engineering (P.O.), University of Minho, Braga, the Centro Hospitalar Alto Ave-EPE (M.C.), Guimarães, Portugal, the Neonatology Unit, University Hospital La Paz (S.A.), the Instituto de Investigaciones Biomédicas Alberto Sols, Centro Mixto Consejo Superior de Investigaciones Científicas-Universidad Autónoma de Madrid (S.A., G.E.), and the Departamento de Didáctica y Organización Escolar, Facultad de Educación-

Universidad Complutense de Madrid (B.S.), Madrid, Spain

Supported by the Portuguese Science Foundation (FCT)FEDER (POCTI_PSI_60948_2004) and Integrated Actions for exchange of scientists "Portugal-Spain E-84/ 2006" (by Fundação para a Ciência e Tecnologia, Portugal and by Ministerio de Educacion y Ciencia, Spain). The authors declare no conflicts of interest.

0022-3476/\$ - see front matter. Copyright $\odot 2011$ Mosby Inc. All rights reserved. 10.1016/j.jpeds.2011.02.034 
Although there is clear evidence that thyroid impairment, whatever its cause, compromises development of the central nervous system, studies are still lacking on the identification of a marker(s) that may predict deleterious consequences for the child throughout development. We performed a longitudinal study to assess correlations of maternal thyroid function in the three trimesters of pregnancy, with that of the child's in the neonatal period, and the child's cognitive, motor, and behavioral development to 2 years of age, in the context of iodine deficiency.

\section{Methods}

The study was carried out at the Centro Hospitalar do Alto Ave, EPE-Guimarães, Portugal. Between January of 2003 and December of 2005, 140 pregnant women, consecutively entering the antenatal clinic, were invited to assess thyroid function during and after pregnancy. The exclusion criteria comprised use of drugs or iodinated antiseptics, pregnancy with multiple fetuses, history of previous diabetes, infertility treatment, malformation of the fetus, known thyroidal and other endocrine dysfunctions, and heavy smoking (more than 10 cigarettes/d). One pregnancy terminated with a fetal loss, six pregnancies were of multiple fetuses, one newborn died in the neonatal intensive care unit, and no data were available for one child. Of 131 children born, those with risk factors for delayed outcome (severe neonatal disease, chronic condition, long-term medication, severe disability, gestational age less than 34 weeks, birth weight less than $2000 \mathrm{~g}$, single-parent family) were excluded, as well as those who had fewer than two psychomotor development evaluations. Eighty-six children remained for the complete study. Newborns were evaluated on day 3 after birth in the context of the national screening for congenital hypothyroidism and in the outpatient clinic at 12,18, and 24 months of age. The study design and procedures were approved by the hospital's research ethical committee. All women gave informed written consent for their enrollment and that of their offspring. Demographic and clinical information of the mothers and progeny was obtained and adjusted for potential confounding effects: maternal age, parity, socioeconomic-cultural status, length of breast feeding, use of alcohol and tobacco during pregnancy, children's sex, gestational age, type of delivery, Apgar's score, birth weight, body length, and head circumference. The social, economic, and cultural status was assessed by the Graffar scale, which includes information on the type of employment and education of the women and their partners, family income, characteristics of the house and type of neighborhood. ${ }^{21}$

\section{Assessment of lodine Status and Thyroid Function}

The following tests were performed on the serum of neonates: total thyroxine $\left(\mathrm{TT}_{4}\right)$, free $\mathrm{T}_{4}\left(\mathrm{FT}_{4}\right)$, and total triiodothyronine $\left(\mathrm{TT}_{3}\right)$ using of the DYNOtest radioimmunoassay reagents (Brahms Diagnostica GmbH, Berlin, Germany).
When there was insufficient serum to determine all thyroid hormone test results, the order of choice for the analysis was $\mathrm{TT}_{4}, \mathrm{FT}_{4}$, and $\mathrm{TT}_{3}$. Maternal thyroid hormones and urinary iodine concentrations in the three trimesters of pregnancy and until 1 year after delivery, including offspring thyroid-stimulating hormone (TSH) and urinary iodine levels in the neonatal period, were reported previously. ${ }^{22,23}$ Because $\mathrm{FT}_{4}$ kits used for diagnosis do not account for changes in the concentration of thyroid hormone carrier proteins, such as is the case during pregnancy (because of the increase in the concentration of thyroxinebinding globulin), and because we were searching for a predictive marker, we further evaluated $\mathrm{FT}_{4}$ in the first trimester of pregnancy by use of two additional measurement methods in a selected number of first-trimester samples (systematic sampling of still available samples) by use of two other independent tests: the Immunotech $\mathrm{FT}_{4}$ radioimmunosorbent assay kit (Beckman Coulter, Prague, Czech Republic) that uses the same methodological principle as the one by Brahms; and by equilibrium dialysis with the Direct Free $\mathrm{T}_{4}$ by Dialysis kit (IVD Technologies, Santa Ana, California).

\section{Assessment of Infant's Development}

Infant's development was assessed by the Bayley Scale of Infant Development, version $\mathrm{I}^{24}$ at 12,18 , and 24 months. This instrument is intended to measure a child's level of development in the cognitive, motor and behavior domains. The Bayley Scale of Infant Development evaluation is performed by presenting a series of test materials to the child and scoring responses by age to convert into the Mental Development Index (MDI) and the Psychomotor Development Index (PDI). The normal average score is of 100 , with a SD of 16. A group difference between 0.5 to $1 \mathrm{SD}$ ( 8 to 16 index points) is considered clinically relevant. Infants are classified as significantly delayed when MDI or PDI is $<68$ ( $>2$ SD under the mean); mildly delayed when having an index between 68 and 83 ( 1 to 2 SD under the mean); within normal limits between 84 and 116 and accelerated when $>116$. Behavior is evaluated by the Infant Behavior Record, a scale that provides supplementary information gained from the mental and motor scales. ${ }^{24}$

\section{Statistical Analyses}

Data are presented as mean $\pm \mathrm{SD}$. Comparisons were made by use of the $t$ test or the nonparametric Mann-Whitney test. Correlations between neonatal and maternal variables were performed with the Pearson correlation or Spearman rank correlation tests. ANOVA was used to compare several groups. Multiple comparisons were studied through the Tukey test. Receiver operator characteristic analysis was used to define thyroid hormones cutoff points. Linear regression models were studied for the relation of behavior variables and development. Values were considered significant when $P<.05$. All tests were two-sided. Statistical analyses were performed with the SPSS 17 software package (SPSS Inc, Chicago, Illinois). The Bland-Altman method ${ }^{25}$ was used to 
Table I. Results of infant mental and psychomotor development assessments at the ages of 12, 18, and 24 months

\begin{tabular}{|c|c|c|c|c|c|c|}
\hline & \multicolumn{3}{|c|}{ MDI } & \multicolumn{3}{|c|}{ PDI } \\
\hline & $\begin{array}{c}12 \text { mo } \\
(n=79)\end{array}$ & $\begin{array}{c}18 \mathrm{mo} \\
(\mathrm{n}=74)\end{array}$ & $\begin{array}{c}24 \text { mo } \\
(n=86)\end{array}$ & $\begin{array}{c}12 \text { mo } \\
(n=79)\end{array}$ & $\begin{array}{c}18 \text { mo } \\
(n=74)\end{array}$ & $\begin{array}{c}24 \text { mo } \\
(n=86)\end{array}$ \\
\hline Score (mean \pm SD) & $97.2 \pm 17.5$ & $98.2 \pm 15.0$ & $100.2 \pm 18.2$ & $93.7 \pm 11.4$ & $96.4 \pm 12.9$ & $95.7 \pm 11.3$ \\
\hline Accelerated (no.) & 10 & 3 & 15 & 1 & 5 & 2 \\
\hline Within normal limits (no.) & 56 & 57 & 55 & 62 & 61 & 73 \\
\hline Mildly delayed (no.) & 9 & 11 & 12 & 14 & 6 & 11 \\
\hline Significantly delayed (no.) & 4 & 3 & 4 & 2 & 2 & 0 \\
\hline Mildly and significantly delayed (\%) & 16.5 & 18.9 & 18.6 & 20.3 & 10.8 & 12.8 \\
\hline
\end{tabular}

determine whether the $\mathrm{FT}_{4}$ values obtained from the three different measurement methods were comparable.

\section{Results}

\section{Children's Characterization}

Enrolled infants $(\mathrm{n}=86)$ comprised 40 girls and 46 boys, born by vaginal delivery in $60 \%$ of the cases, with mean gestational age of 38.2 weeks $(\mathrm{SD}=1.6)$, mean birth weight of $3187 \mathrm{~g}(\mathrm{SD}=440)$, mean birth length of $48.8 \mathrm{~cm}(\mathrm{SD}=$ $2.1)$, and mean cephalic perimeter of $34.6 \mathrm{~cm}(\mathrm{SD}=1.4)$. All neonates had an Apgar score at the first minute $\geq 6$ and at the fifth minute $\geq 8$. None had abnormal results on the national screening program for congenital hypothyroidism. Newborn percentile for thyroid parameters were for $\mathrm{TT}_{4}$ $(\mathrm{ug} / \mathrm{dL})(\mathrm{n}=80)$, 10th percentile: 12.0; 50th percentile: 17.7; and 90th percentile: 21.5; for $\mathrm{FT}_{4}(\mathrm{pg} / \mathrm{mL})(\mathrm{n}=79)$, 10th percentile: 13.7 ; 50 th percentile: 18.9 ; and 90 th percentile: 22.8; and for $\mathrm{TT}_{3}(\mathrm{nmol} / \mathrm{L})(\mathrm{n}=60)$, 10th percentile: 1.8 ; 50th percentile: 2.2; and 90th percentile: 3.0. Eight children $(9.3 \%)$ were born before 37 weeks gestational age, and eight had low birth weight $(<2500 \mathrm{~g})$.

\section{Mother's Characterization}

The mothers, part of a larger population for whom detailed characterization of thyroid function has been previously described, ${ }^{22,23}$ had a mean age of 30.8 years old $(\mathrm{SD}=6.5)$, one-half with a medium-high socioeconomic status and 2.5 average pregnancies $(S D=1.6)$. Eight women had antithyroidal antibodies with serum thyroid hormones levels (including $\mathrm{FT}_{4}$ ), similar to those women without measurable antibodies. In the first trimester of pregnancy, 10th percentile for $\mathrm{FT}_{4}$ was of $9.0 \mathrm{pg} / \mathrm{mL}$ and for 50th to 90th percentile was 11.1 to $13.7 \mathrm{pg} / \mathrm{mL}$; five women had both $\mathrm{FT}_{4}$ levels $<10$ th percentile and $\mathrm{UI}<50 \mu \mathrm{g} / \mathrm{L}$. Two cases had $\mathrm{FT}_{4}<10$ th percentile in the first and third trimesters. Women of higher socioeconomic class and less parity had higher UI values. There were no differences in women regarding age, previous pregnancies, and socioeconomic status related to $\mathrm{FT}_{4}$ levels. The subset of the initial sample, for which confirmatory testing was performed, (91/146 for the Beckman Coulter kit and 70/146 for the equilibrium dialysis kit), showed good agreement with a $95 \%$ CI with the Bland-Altman method of comparison. ${ }^{25}$ Therefore, for monitoring purposes, the data suggest that the different measurement approaches used were appropriate and concordant.

Children's characteristics such as sex, gestational age, type of delivery, Apgar score, birth, body length, and cephalic perimeter at birth and length of breastfeeding were not statistically different comparing mothers with $\mathrm{FT}_{4}$ levels $<10$ th percentile $(n=8)$ to 50 th to 90 th percentile $(n=36)$ in the first trimester. For the same measurements no differences were noted between mothers with $\mathrm{UI}<50 \mu \mathrm{g} / \mathrm{L}(\mathrm{n}=36) \mathrm{com}-$ pared with mothers with $>50 \mu \mathrm{g} / \mathrm{L}(\mathrm{n}=47)$.

\section{Developmental Assessment}

Global results of psychomotor evaluations are shown in Table I. Of note, more than $10 \%$ of children displayed mild-to-significant delay at all assessment times (12, 18, and 24 months). Mental development index correlated negatively with the socioeconomic status at 18 and 24 months (Pearson coefficient of correlation of -0.67 and -0.88 , respectively). No correlations were found between psychomotor development and children's sex, Apgar score, gestational age (only term babies were considered) and birth weight (only babies with birth weight $>2500$ g were considered), or mother's age, presence of antithyroidal antibodies, or previous pregnancies. Infants born by eutocic deliveries tended to perform better, however, without statistical significance.

\section{Relationship between Mother's Thyroid Status and Infant Development}

The relationship between maternal iodine and thyroid status, at different times of pregnancy, was assessed for mothers with altered thyroid function (cases) compared with those within normal limits (control subjects), on the progeny's psychomotor development. Serum thyroid level parameters were defined as $\mathrm{TT}_{4}, \mathrm{FT}_{4}, \mathrm{TT}_{3}$, and $\mathrm{FT}_{3}$, cases with levels $<10$ th percentile and control subjects 50th to 90th percentile; TSH, cases with levels $>90$ th percentile and control subjects 10th to 50th percentile; UI, cases with levels $<50 \mu \mathrm{g} / \mathrm{L}$ and control subjects $\geq 50 \mu \mathrm{g} / \mathrm{L}$.

Table II lists the comparisons of the progeny's development at the different ages and thyroid function by trimesters; only those differences statistically significant (and clinically relevant) and nonstatistically significant but clinically relevant (group differences between 0.5 to $1 \mathrm{SD}$ ) 
Table II. Relation between maternal iodine and thyroid status, for mothers with altered thyroid function (cases) compared with those within normal limits (controls), on the progeny's psychomotor development

\begin{tabular}{|c|c|c|c|c|c|}
\hline \multirow[b]{2}{*}{ Effect } & \multicolumn{2}{|c|}{ Score $($ mean \pm SD) } & \multicolumn{3}{|c|}{ Mother } \\
\hline & Cases & Control subjects & Analyte & Trimester & Cases (control subjects) \\
\hline \multicolumn{6}{|l|}{$\mathrm{MDI}$} \\
\hline \multicolumn{6}{|l|}{$12 \mathrm{mo}$} \\
\hline & $90.7 \pm 14.5$ & $102.6 \pm 18.1$ & $\Pi_{3}$ & $3 r d$ & $7(25)$ \\
\hline & $77.7 \pm 17.9^{\star}$ & $99.3 \pm 17.6$ & $\mathrm{FT}_{3}$ & $3 r d$ & $9(33)$ \\
\hline & $89.4 \pm 19.5$ & $98.3 \pm 14.8$ & $\mathrm{FT}_{4}$ & 3rd & $7(25)$ \\
\hline \multicolumn{6}{|l|}{$18 \mathrm{mo}$} \\
\hline & $88.9 \pm 12.8^{\star}$ & $99.9 \pm 20.8$ & UI & $3 r d$ & $23(42)$ \\
\hline & $84.2 \pm 35.8$ & $96.8 \pm 16.4$ & $\mathrm{TT}_{4}$ & 3rd & $6(23)$ \\
\hline \multicolumn{6}{|l|}{$24 \mathrm{mo}$} \\
\hline & $93.8 \pm 16.3^{*}$ & $104.7 \pm 18.2$ & UI & $1 \mathrm{st}$ & $36(47)$ \\
\hline & $94.2 \pm 15.1^{*}$ & $103.5 \pm 20.7$ & UI & $3 r d$ & $26(47)$ \\
\hline & $92.6 \pm 19.4$ & $103.4 \pm 19.0$ & $\mathrm{FT}_{4}$ & $1 \mathrm{st}$ & $8(36)$ \\
\hline & $91.1 \pm 21.4$ & $100.7 \pm 17.2$ & $\mathrm{FT}_{3}$ & 3rd & $9(33)$ \\
\hline \multicolumn{6}{|l|}{ PDI } \\
\hline \multicolumn{6}{|l|}{$18 \mathrm{mo}$} \\
\hline & $92.4 \pm 13.4^{*}$ & $99.1 \pm 12.3$ & UI & $1 \mathrm{st}$ & $28(44)$ \\
\hline & $92.1 \pm 13.8^{\star}$ & $98.7 \pm 12.0$ & Ul & $3 r d$ & $23(42)$ \\
\hline & $85.9 \pm 20.0^{*}$ & $98.7 \pm 12.5$ & $\mathrm{FT}_{4}$ & $1 \mathrm{st}$ & $7(28)$ \\
\hline & $86.0 \pm 31.2$ & $97.0 \pm 14.4$ & $\Pi_{3}$ & 2nd & $3(29)$ \\
\hline \multicolumn{6}{|l|}{$24 \mathrm{mo}$} \\
\hline & $84.4 \pm 10.9^{\star}$ & $98.0 \pm 9.5$ & $\mathrm{FT}_{4}$ & $1 \mathrm{st}$ & $8(36)$ \\
\hline & $87.2 \pm 14.5$ & $97.2 \pm 12.0$ & $\mathrm{TT}_{3}$ & 2nd & $5(34)$ \\
\hline
\end{tabular}

All MDI and PDI scores shown are clinically relevant. $*(P<.05)$.

are shown. Serum values of TSH did not correlate to the children's development at any time during pregnancy. $\mathrm{TT}_{4}$ and $\mathrm{TT}_{3}$ were not statistically significantly different but displayed a trend for children's development; $\mathrm{FT}_{4}, \mathrm{FT}_{3}$, and iodine related significantly to psychomotor development. Women with levels of $\mathrm{FT}_{4}<10$ th percentile had hypothyroxinemia or normal thyroid function. The mothers of the 15 children with accelerated mental performance by 24 months, compared with mothers of children with lower MDI, had lower $\mathrm{FT}_{3}$ levels in the first trimester (mean $\pm \mathrm{SD}: 3.9 \pm 0.5 \mathrm{pg} / \mathrm{mL}$ vs $4.4 \pm 0.6 \mathrm{pg} /$ $\mathrm{mL}, P<.01)$, and none had $\mathrm{FT}_{4}$ levels $<10$ th percentile.

Receiver operator characteristic analysis was performed to determine a cutoff value of maternal $\mathrm{FT}_{4}$ that could be predictive of having a child with abnormal psychomotor development. Mothers with first-trimester $\mathrm{FT}_{4}$ levels $<10 \mathrm{pg} / \mathrm{mL}$ (approximately $25 \%$ of our sample) had an OR of 2.1 for having a child mildly or significantly delayed (with a PDI at 24 months $<84$, which is $<1 \mathrm{SD}$ below the mean).

The correlation between neonatal thyroid status and children's development also was assessed. Significant (although weak) correlations were found between neonatal serum levels of $\mathrm{TT}_{3}$ and MDI 12 months (Pearson coefficient $=-0.46$ ), serum TSH and MDI 18 months (Pearson coefficient $=-0.27$ ) and $\mathrm{FT}_{3}$ levels and PDI 24 months (Pearson coefficient = $-0.52)$.

\section{Effect of Maternal First-Trimester UI and $\mathrm{FT}_{4}$ Levels on Infant's Behavior}

The relation of maternal UI (Table III) and $\mathrm{FT}_{4}$ levels in the first trimester with infant's behavior was assessed by BRI.
Children born from hypothyroxinemic euthyroid mothers showed less endurance at 12 months (less able to remain responsive to the demands of the tests; non-parametric comparisons, cases' mean rank $=13$, control subjects' mean rank $=22, P<.05)$, and were fearless of strange situations by the age of 18 months (cases' mean rank $=10$, controls' mean rank $=19, P<.05$ ). Children born from iodinedeficient mothers performed with less endurance and attention and had lower persistence in a goal-direct effort, exhibiting a higher level of activity and reactivity (Table III).

\section{Relation between Behavior, MDI, and PDI}

At all assessment points (12, 18, and 24 months) the three motivation variables of behavior (endurance, intentionality, and attention span) correlated positively with each other, as well as with the MDI. The level of activity correlated negatively with endurance, intentionality, and attention span, having a negative impact on MDI (Table IV). Moreover, endurance, intentionality, and attention span at 12 months correlated with MDI and PDI at 18 months (data not shown). To establish a causal link between behavior items and MDI at 24 months, regression models were performed. Fifty percent of the observed variability on mental development at 24 months was explained by endurance at 18 months $(P=.023)$ and intentionality $(P=.004)$ and endurance at 24 months $(P=.032)$ as explanatory variables.

\section{Discussion}

Our study is the most complete longitudinal assessment to date of the importance of maternal thyroid hormone and 
Table III. Differences in children's behavior scale according to mothers' urinary iodine concentration in the first trimester of pregnancy

\begin{tabular}{|c|c|c|}
\hline \multirow[b]{2}{*}{ Characteristic } & \multicolumn{2}{|c|}{ Mean rank } \\
\hline & $\begin{array}{c}\text { Cases } \\
\text { (UI }<50 \mu \mathrm{g} / \mathrm{L})\end{array}$ & $\begin{array}{l}\text { Control subjects } \\
\text { (UI } \geq 50 \mu \mathrm{g} / \mathrm{L})\end{array}$ \\
\hline \multicolumn{3}{|l|}{$12 \mathrm{mo}$} \\
\hline Fearfulness & $32(n=36)$ & $44(n=39)$ \\
\hline Attention span & $33(n=36)$ & $44(n=40)$ \\
\hline \multicolumn{3}{|l|}{$18 \mathrm{mo}$} \\
\hline Fearfulness & $25(n=27)$ & $41(n=41)$ \\
\hline Looking around & $41(n=27)$ & $32(n=41)$ \\
\hline Manipulation (banging toys/hands) & $28(n=27)$ & $39(n=41)$ \\
\hline Attention span & $29(n=28)$ & $41(n=43)$ \\
\hline Intentionality (persistence in a goal-directed effort) & $30(n=28)$ & $40(n=43)$ \\
\hline Endurance (ability to remain responsive to the demands of the test) & $30(n=28)$ & $40(n=43)$ \\
\hline Level of energy & $42(n=28)$ & $32(n=43)$ \\
\hline \multicolumn{3}{|l|}{$24 \mathrm{mo}$} \\
\hline Intentionality & $33(n=35)$ & $48(n=47)$ \\
\hline Reactivity (sensitivity or excitability to the environment or arousal) & $47(n=35)$ & $37(n=47)$ \\
\hline
\end{tabular}

Nonparametric comparisons. All values (cases) significant at $P<.05$.

iodine status during pregnancy on infant/child neurodevelopment. Altogether, our study demonstrates the close relation of different areas of development: changes in behavior appear earlier and impact on later development. In contrast, the correlation found between neonatal thyroid status and development was weak and not consistent. Therefore the major impact of thyroid hormones seems to occur during fetal life, especially before the onset of fetal thyroid function. These observations highlight the need for monitoring thyroid function during early pregnancy, corroborating data from other studies. ${ }^{1,6}$

The results obtained from maternal thyroid and iodine status show that the progeny's psychomotor development related to all thyroid analytes except serum TSH levels, probably because these women had normal thyroid function. However, it seems that maternal $\mathrm{FT}_{4}$ in the first trimester of pregnancy is a major determinant of the offspring's development. Accordingly, the relationship between early maternal serum $\mathrm{FT}_{4}$ levels and children's development have been highlighted in the literature. ${ }^{12-16,26,27}$ Altogether, these studies, including our findings, substantiate that the availability of maternal $\mathrm{FT}_{4}$ to the developing fetal brain is of greater importance than that of $\mathrm{TT}_{3}$, given that fetal brain $\mathrm{TT}_{3}$ is almost entirely generated locally from fetal serum $\mathrm{T}_{4}$. Considering that fetal thyroid function is substantial from 20 weeks of gestation, reaching appreciable amounts by the third trimester, and that thyroid hormone receptors are found in fetal brain after 10 weeks of gestation, it is thought that fetal $\mathrm{TT}_{3}$ brain levels depend on $\mathrm{FT}_{4}$ serum levels. In turn, $\mathrm{FT}_{4}$ levels depend on the amount of maternal $\mathrm{FT}_{4}$ that reaches the placental barrier. ${ }^{1,6} \mathrm{We}$ found that maternal hypothyroxinemia (low levels of $\mathrm{FT}_{4}$ ) is associated with an increased risk of progeny's psychomotor delay (OR of 2.1) and a cutoff of $\mathrm{FT}_{4}$ could be established to predict that risk. This was independent of the cause of hypothyroxinemia, supporting the hypothesis that any condition leading to maternal hypothyroxinemia can im- pact the progeny's development. ${ }^{1}$ We found no differences in thyroid hormone levels according to the presence of thyroid antibodies.

The finding that maternal serum $\mathrm{FT}_{4}$ levels after midgestation seem not to be related with development outcome does not mean that the fetal brain no longer requires maternal thyroid hormones after the earlier phases of development. Iodine crosses the placenta and is critical for building fetal thyroid stores and for fetal thyroid hormone synthesis. In our study, $\mathrm{FT}_{4}$ levels in the third trimester had clinically relevant impact on MDI at 12 months and iodine in the last trimester also was associated with differences in MDI/PDI at 18 months and with MDI at 24 months.

The progeny of mothers with hypothyroxinemia or iodine deficiency had a common developmental phenotype: decreased PDI by 18 months that at 24 months persisted and presented with mental impairment. However, by 12 months, while presenting a "normal" psychomotor development, as classified by the developmental indexes MDI and PDI, within a range of $100 \pm 16$, these children exhibited lower levels of endurance and a shorter attention span, which seemed associated with some disruption in normal development in later ages. Specifically, mental development was related with intentional behavior (conduct toward a target) and attention. We found that the pattern of deficit of attention, perseverance, and intentionality, with a higher level of activity (especially after 18 months) correlated negatively with the mental index on later ages (data not shown). Furthermore, changes in endurance and intentionality accounted for $50 \%$ of the variability of mental development at 24 months. Although we cannot prove that attention deficit itself accounts for the variation in mental development at 24 months, as others described at 3 months, ${ }^{28}$ endurance and intentionality are deeply linked to attention. In fact, endurance (understood as the ability to remain responsive to the demands of the test or the environment, or to persevere) and attention 


\begin{tabular}{|c|c|c|c|c|c|c|}
\hline & \multicolumn{4}{|c|}{ Behavior } & \multirow[b]{2}{*}{ MDI } & \multirow[b]{2}{*}{ PDI } \\
\hline & Endurance & Attention & Intentionality & Level activity & & \\
\hline \multicolumn{7}{|l|}{$12 \mathrm{mo}$} \\
\hline Endurance & - & & & & & \\
\hline Attention & 0.72 & - & & & & \\
\hline Intentionality & 0.71 & 0.76 & - & & & \\
\hline Level activity & NS & NS & NS & - & & \\
\hline MDI & 0.38 & 0.27 & 0.33 & NS & - & \\
\hline PDI & NS & NS & NS & NS & 0.46 & - \\
\hline \multicolumn{7}{|l|}{$18 \mathrm{mo}$} \\
\hline Endurance & - & & & & & \\
\hline Attention & 0.50 & - & & & & \\
\hline Intentionality & 0.45 & 0.83 & - & & & \\
\hline Level activity & NS & -0.49 & -0.39 & - & & \\
\hline MDI & 0.40 & 0.43 & 0.48 & -0.25 & - & \\
\hline PDI & NS & NS & 0.29 & NS & 0.54 & - \\
\hline \multicolumn{7}{|l|}{$24 \mathrm{mo}$} \\
\hline Endurance & - & & & & & \\
\hline Attention & 0.57 & - & & & & \\
\hline Intentionality & 0.48 & 0.80 & - & & & \\
\hline Level activity & -0.23 & -0.62 & -0.49 & - & & \\
\hline MDI & 0.55 & 0.47 & 0.58 & -0.37 & - & \\
\hline PDI & 0.43 & NS & NS & NS & 0.49 & - \\
\hline
\end{tabular}

All data shown expressed as Spearman correlation coefficient. Values significant at $P<.05$, except when noted nonsignificant (NS).

during the first year of life are described to correlate with mental tests, intelligence quotient, better performance in operative conditioning tests, academic performance, and learning skills. ${ }^{29}$ The link between attention and thyroxine levels has been previously reported ${ }^{17,15,30}$ and may also underlie our observations.

Several limitations of the study should be noted, mainly the small size of the groups and the fact the mothers were selected from a hospital surveillance. Some bias also might have been introduced in the development assessment because the pediatrician who performed the development evaluation had access to the complete clinical history of the mother and child and also because assessing the development is in itself an early intervention. It also must be underlined that children's thyroid function was only studied at birth, and use of urinary iodine excretion to evaluate iodine status can only be done for epidemiologic purposes or cross-section studies. Nonetheless, while attending to the knowledge that the final outcome in development is influenced by many variables, we excluded most reported risks and protective factors related to development ${ }^{10,31}$ and solely included children with at least two assessments of development.

Although delayed motor performance found in our study seems to be a mild disability, this may influence the possibilities of the child to explore the environment and, consequently, impair development in general. ${ }^{31}$ In our cohort, one in four children had a relative risk of psychomotor development delay (both mild and significant) 2.1 times higher when related to maternal $\mathrm{FT}_{4}$ levels $<10 \mathrm{pg} / \mathrm{mL}$ in the first trimester of pregnancy. Even though obstetric associations worldwide have not reached consensus on universal study of thyroid function in pregnant women, it would seem wise to prescribe iodine supplements periconceptionally and during pregnancy and lactation, because the negative effects on development and behavior might be prevented through preemptive action. ${ }^{7,27}$

We are thankful to Profs. Isabel Soares and Maria Raul Xavier for critical discussions on the behavioral analysis.

Submitted for publication Aug 12, 2010; last revision received Jan 6, 2011; accepted Feb 25, 2011.

Reprint requests: Joana Almeida Palha, PhD, Life and Health Sciences Research Institute (ICVS), School of Health Sciences, University of Minho, Campus Gualtar, 4710-057 Braga, Portugal. E-mail: japalha@ecsaude. uminho.pt

\section{References}

1. Escobar GM, Obregón MJ, Escobar del Rey F. Is neuropsychological development related to maternal hypothyroidism or to maternal hypothyroxinemia? J Clin Endocrinol Metab 2000;85:3975-87.

2. Lavado-Autric R, Ausó E, García-Velasco JV, Arufe M del C, Escobar del Rey, Berbel P, et al. Early maternal hypothyroxinemia alters histogenesis and cerebral córtex cytoarchitecture of the progeny. J Clin Invest 2003; 111:1073-82.

3. Auso E, Lavado-Autric R, Cuevas E, del Rey FE, Escobar GM, Berbel P. A moderate and transient deficiency of maternal thyroid function at the beginning of fetal neocorticogenesis alters neuronal migration. Endocrinology 2004;145:4037-47.

4. Cuevas E, Ausó E, Telefont M, Escobar GM, Sotelo C, Berbel P. Transient maternal hypothyroxinemia at onset of corticogenesis alters tangential migration of medial ganglionic eminence-derived neurons. Eur J Neurosci 2005;22:541-51.

5. Zoeller RT, Rovet J. Timing of thyroid hormone action in the developing brain: clinical observations and experimental findings. J Neuroendocrinol 2004;16:809-18.

6. Escobar GM, Obregón MJ, del Rey FE. Iodine deficiency and brain development in the first half of pregnancy. Public Health Nutr 2007;10:1554-70.

7. Andersson M, de Benoist B, Darnton-Hill I, Delange F. Iodine deficiency in Europe: a continuing public health problem. Geneva: World Health Organization; 2007. 
8. Piaget J. The stages of the intellectual development of the child. Bull Menninger Clin 1962;26:120-8.

9. Bronfenbrenner U. Ecology of the family as a context for human development: research perspectives. Dev Psychol 1986;22:723-42.

10. Sameroff AJ. Understanding the social context of early psychopathology. In: Nospitz J, ed. Handbook of child and adolescent psychiatry. New York: Wiley; 1997. p. 224-34.

11. Haddow JE, Palomaki GE, Allan WC, Williams JR, Knight GJ, Gagnon J, et al. Maternal thyroid deficiency during pregnancy and subsequent neuropsychological development of the child. N Engl J Med 1999;341:54955.

12. Li Y, Shan Z, Teng W, Yu X, Li Y, Fan C, et al. Abnormalities of maternal thyroid function during pregnancy affect neuropsychological development of their children at 25-30 months. Clin Endocrinol 2010 (Oxf) 2010;72:825-9.

13. Pop VJ, Kuijpens JL, van Baar AL, Verkerk G, van Son MM, de Vijlder JJ, et al. Low maternal free thyroxine concentrations during early pregnancy are associated with impaired psycho-motor development in infancy. Clin Endocrinology (Oxf) 1999;50:149-55.

14. Pop VJ, Brouwers EP, Vader HL, Vulsma T, van Baar AL, de Vijlder JJ. Maternal hypothyroxinaemia during early pregnancy and subsequent child development: a 3-year follow-up study. Clin Endocrinol (Oxf) 2003;59:282-8.

15. Kooistra L, Crawford S, van Baar AL, Browers EP, Pop VJ. Neonatal effects of maternal hypothyroxinemia during early pregnancy. Pediatrics 2006;117:161-7.

16. Velasco I, Carreira M, Santiago P, Muela JA, Garcia-Fuentes E, SánchezMuñoz B, et al. Effect of iodine prophylaxis during pregnancy on neurocognitive development of children during the first two years of life. J Clin Endocrinol Metab 2009;94:3234-41.

17. Vermiglio F, Lo Presti VP, Moleti M, Sidoti M, Tortorella G, Scaffidi G, et al. Attention deficit and hyperactivity disorders in the offspring of mothers exposed to mild-moderate iodine deficiency: a possible novel iodine deficiency disorder in developed countries. J Clin Endocrinol Metab 2004;89:6054-60.

18. Bernal J, Guadano-Ferraz A, Morte B. Perspectives in the study of thyroid hormone action on brain development and function. Thyroid 2003;13:1005-12.

19. Connolly KJ, Pharoah POD. Iodine deficiency, maternal thyroid levels in pregnancy and developmental disorders in children. In: DeLong GR,
Robbins J, Condliffe, eds. Iodine and the brain. New York: Plenum Press; 1989. p. 317-31.

20. Man EB, Jones WS, Holden RH, Mellits WS. Thyroid function in human pregnancy. 8. Retardation of progeny aged 7 years; relationships to maternal age and maternal thyroid function. Am J Obstet Gynecol 1971;11: 905-16.

21. Graffar M. Une methode de classification social d'echantillons de la population. Courrier 1956;6:445-59.

22. Costeira MJ, Oliveira P, Ares S, de Escobar GM, Palha JA. Iodine status of pregnant women and their progeny in the Minho region of Portugal. Thyroid 2009;19:157-63.

23. Costeira MJ, Oliveira P, Ares S, Roque S, Escobar GM, Palha JA. Parameters of thyroid function throughout and after pregnancy in an iodinedeficient population. Thyroid 2010;20:995-1001.

24. Bayley N. Manual for the Bayley Scales of Infant Development. New York: Psychological Corporation; 1969.

25. Bland JM, Altman DG. Statistical methods for assessing agreement between two methods of clinical measurement. Lancet 1986;1(8476):30710 .

26. Kasatkina EP, Samsonova LN, Ivakhnenko VN, Ibragimova GV, Ryabykh AV, Naumenko LL, et al. Gestational hypothyroxinemia and cognitive function in the offspring. Neurosci Behav Physiol 2006;36: 619-24.

27. Berbel P, Obregón MJ, Bernal J, Escobar del Rey F, Morreale de Escobar G. Iodine supplementation during pregnancy: a public health challenge. Trends Endocrinol Metab 2007;18:338-43.

28. Simic N, Asztalos EV, Rovet J. Impact of neonatal thyroid hormone insufficiency and medical morbidity on infant neurodevelopment and attention following preterm birth. Thyroid 2009;19:395-401.

29. Engle PL, Black MM, Behrman JR, Cabral de Mello M, Gertler PJ, Kapiriri L, et al., International Child Development Steering Group. Strategies to avoid the loss of developmental potential in more than 200 million children in the developing world. Lancet 2007;369:229-41.

30. Mirabella G, Feig D, Astzalos E, Perlman K, Rovet JF. The effect of abnormal intrauterine thyroid hormone economies on infant cognitive abilities. J Pediatr Endocrinol Metab 2000;13:191-4.

31. Janssen AJ, Nijhuis-van der Sanden MW, Akkermans RP, Oostendorp RA, Kollée LA. Influence of behavior and risk factors on motor performance in preterm infants at age 2 to 3 years. Dev Med Child Neurol 2008;50:926-31. 